\title{
Analytical and Numerical Solutions to Selected Research Problems in Geomechanics and Geohydraulics
}

\author{
SUDIP BASACK ${ }^{1 *}$, GHRITARTHA GOSWAMI ${ }^{2}$, SANJAY NIMBALKAR ${ }^{3}$ \\ ${ }^{1}$ Elitte College of Engineering, Affiliated: Maka University of Technology, \\ Kolkata 700113, INDIA \\ ${ }^{2}$ North Eastern Regional Institute of Science and Technology Nirjuli, \\ Arunachal Pradesh, INDIA \\ ${ }^{3}$ School of Civil and Environmental Engineering, University of Technology Sydney, \\ Ultimo, AUSTRALIA
}

\begin{abstract}
Geomechanical and geohydraulic engineering is a promising study area with several emerging research concerns. Most of such problems requires advanced level of mathematics to arrive at specific solutions. A wide range of approaches includes several analytical and numerical techniques for better understanding of such problems. In this paper, a few selected research problems are identified, and their solution techniques are demonstrated. The specific areas relevant to such problems are soil-structure interaction, ground improvement and groundwater hydraulics. This paper presents the problem identification, their mathematical solutions and results as well as pertinent analyses and useful interpretations to practice.
\end{abstract}

Key-Words: - Analytical model, Numerical model, Ground improvement, Groundwater, Pile, Soil

Received: April 12, 2021. Revised: October 6, 2021. Accepted: October 17, 2021. Published: October 31, 2021.

\section{Introduction}

Geotechnical and geoenvironmental engineering is long-standing scientific discipline that covers diversified areas of topics. The soil-structure interaction under complex loading conditions, soft ground improvement for civil infrastructure development, groundwater hydraulics and hydrology are among the emerging topics [1]. The specific research challenges in these study topics necessitate appropriate solutions which demand the application of advanced mathematics [2].

Application of cutting edge analytical and numerical techniques is required to understand the stress distribution patterns, deformation mechanisms, material strength and stiffness alterations, and other properties of geomaterials under complex loading conditions, as well as to analyze the groundwater flow patterns in critical conditions. Specific analytical techniques sometimes involve the application of Fourier series, Laplace transformation, statistics and probability, high order differential equations and their solutions, among others [3]. The numerical techniques, on the other hand, include from finite difference and finite element analyses to more contemporary boundary element modelling in two-dimensional and three-dimensional spaces [4].

This paper covers illustration of the application of mathematical tools to solve a few specific research problems related to geotechnical and geoenvironmental engineering. The issues discussed here are: pile-soil interaction, ground improvement and coastal groundwater management. Solutions to these problems required both analytical and numerical techniques and the use of computer was essentially evident. A brief description to each of the research areas including problem identification, solution techniques together with results and discussions is sequentially presented in this paper.

\section{Torsional Pile-Soil Interaction}

Pile-soil interaction under complex loading condition is a typical research discipline in geotechnical engineering that necessitates sophisticated mathematical operations to arrive at specific solutions [5-6]. The response of pile to torsional loading is a complex mathematical issue that requires both analytical and numerical techniques to obtain the desired solutions [7].

The current problem involves a typical solid cylindrical vertical pile embedded in a semi-infinite uniform soil bed subjected to an axial load $V_{\text {top }}$ and a torsional load $T_{\text {top }}$, as shown in the Fig.1(a). Under imposed loads, the induced stress conditions in a characteristic soil element adjacent to the point ' $A$ ' at the pile-soil interface is shown in Fig.1(b). Fig.1 depicts the basic mathematical model adopted in this study. The figure reveals the complex triaxial stress condition which a typical element adjacent to the interface is subjected to. Such stresses consist of both normal and shear components. Appropriate mathematical solutions are obtained for the applied torsion as static and cyclic, as described in the following sub-sections.

\subsection{Static Torsion: Boundary Element Method}

The pile-soil interaction is initially carried out for static torsion, which means that the imposed load $T_{\text {top }}$ does not change over time. The mathematical modelling presented is actually based on simplified boundary element method, where the stress components acting on the boundary surface of individual pile elements were analyzed and the 
numerical algorithms were developed. The pile and the soil are idealized as elastic-perfectly plastic and hyperbolically nonlinear, respectively. By integrating the appropriate differential equations for torsional stress and displacements, the relevant correlations
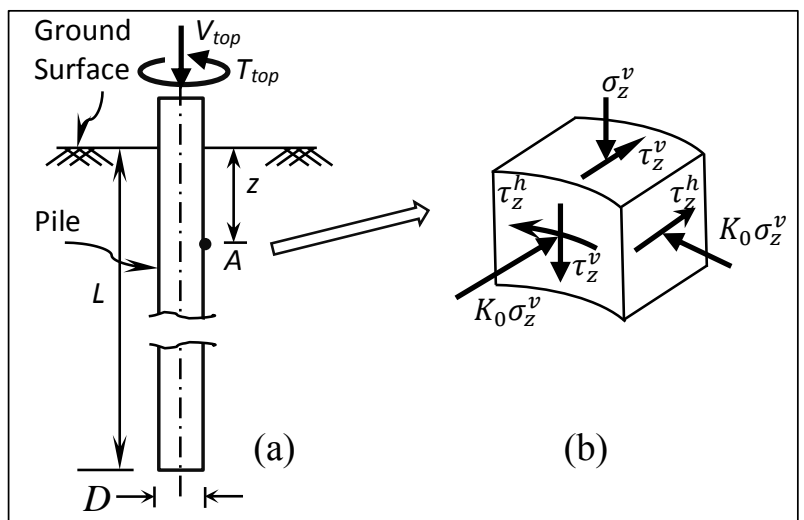

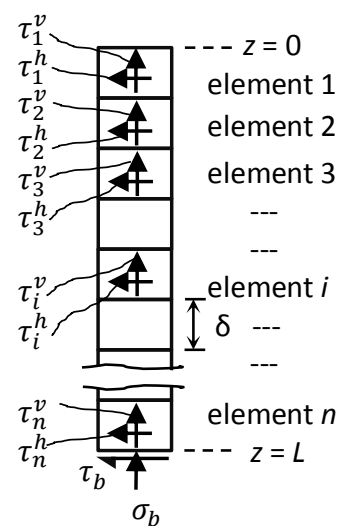

(c)

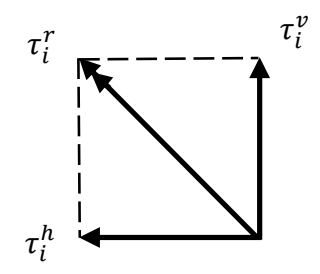

(d)

Fig.1. Problem identification: (a) The idealized problem, (b) Cylindrical stress element, (c) Numerical scheme, and (d) Vectorial stress resultant.

For ultimate torsional capacity and the ultimate twist at ground surface have been obtained, considering yield values of shear stresses in clay and sand. The expressions obtained [8] are given by:

$T_{u}=\int_{0}^{L} \frac{\pi D^{2}}{2} \tau_{z}^{h u} d z+\int_{0}^{2 \pi} \int_{0}^{\frac{D}{2}} \tau_{b}^{u} r^{2} d r d \beta=\frac{\pi D^{2} L}{12} F_{1}$

where, $T_{u}$ is the ultimate torsional capacity of the pile, $\tau_{z}^{h u}$ and $\tau_{b}^{u}$ are the ultimate values of the shear stresses $\tau_{z}^{h}$ and $\tau_{b}$ respectively, $r$ and $\beta$ are the radial and angular distances respectively, and the function $F_{1}$ is given as,

$$
\begin{aligned}
& F_{1}=\alpha\left[\left(6+\frac{1}{r_{L}}\right) c_{u 0}+\left(3-\frac{1}{r_{L}}\right) \eta_{c} L\right] \\
& F_{1}=\tan \delta_{s}\left(\frac{\sigma_{v}^{\prime}}{r_{L}}+3 K_{0} \gamma_{s}^{\prime} L\right)
\end{aligned}
$$

where, $\alpha$ is the adhesion factor, $r_{L}=L / D, c_{u 0}$ is the unit cohesion at ground surface, $\eta_{c}$ is the rate of increase of unit cohesion with depth, $\delta_{s}$ is the effective friction angle, $\sigma_{v}^{\prime}$ is the in-situ effective overburden pressure at $z=L, K_{0}$ is the in-situ earth pressure coefficient and $\gamma_{s}^{\prime}$ is the effective unit weight of sand.

The ultimate angle of twist at the ground surface was evaluated by [8]: $\theta_{z}^{\max }=\frac{T_{u} z}{R_{p}^{t}}-\frac{1}{2} \pi D^{2} \int_{0}^{z}\left(\int_{0}^{z} \tau_{z}^{h u} d z\right) d z+\theta_{b}^{\max }$

where, $\theta_{z}^{\max }$ is the maximum torsional pile displacement at depth $z, R_{p}^{t}$ is the torsional pile rigidity and $\theta_{b}^{\max }$ is the maximum base twist angle. From the above correlation, the maximum angle of twist of pile at the ground surface is obtained by:

$\theta_{0}^{\max }=\frac{T_{u} L}{R_{p}^{t}}\left[1-\frac{\pi D^{2} L}{12 T_{u}} F_{2}+\frac{R_{p}^{t}}{2 T_{u}} F_{3}\right]$

where, the function $F_{2}$ and $F_{3}$ are given by:

$F_{2}=\alpha\left(3 c_{u 0}+\eta_{c} L\right)$

$F_{2}=3 K_{0} \gamma_{s}^{\prime} L \tan \left(\delta_{s}\right)$

$F_{3}=\frac{\alpha\left(c_{u 0}+\eta_{c} L\right)}{\left(1-R_{f}\right)\left(G_{t 0}+\eta_{g} L\right)}$

$F_{3}=\frac{K_{0} \gamma_{s}^{\prime} L \tan \left(\delta_{s}\right)}{\left(1-R_{f}\right)\left(G_{t 0}+\eta_{g} L\right)}$

where, $R_{f}$ is a non-dimensional hyperbolic soil parameter, $G_{t 0}$ is the initial tangent modulus relevant to hyperbolic stress-strain response of soil, whose value was assumed to increase with depth at constant rate of $\eta_{g}$.

To carry out numerical modelling using finite difference technique, the embedded pile is longitudinally divided into $n$ number of equal elements, each having a thickness of $\delta$ and subjected to shear stress components $\tau_{i}^{h}$ and $\tau_{i}^{v}$ in the horizontal and vertical directions, respectively (Fig.1c).

The static torsional analysis is based on torsional and axial equilibrium conditions of pile, given respectively as:

$\pi D \delta \sum_{i=1}^{n} \tau_{i}^{h}+\frac{\pi D^{2}}{4} \tau_{b}=T_{\text {top }}$
$\pi D \delta \sum_{i=1}^{n} \tau_{i}^{v}+\frac{\pi D^{2}}{4} \sigma_{b}=V_{\text {top }}$

The matrix equations have been derived by expansion of the differential equations which are as follows:

$\nabla_{z}^{2} \theta=\frac{2 A}{R_{T}} \tau_{z}^{h}$
$\nabla_{z}^{2} \rho=\frac{\pi D}{R_{A}} \tau_{v}^{h}-\frac{\gamma_{p}}{E_{p}}$

where, $\nabla_{z} \equiv \frac{d^{2}}{d z^{2}}, A$ is the pile cross sectional area, $\gamma_{p}$ and $E_{p}$ are the mass density and Young's modulus of the pile material, $R_{T}$ and $R_{A}$ are the torsional and axial rigidity of the pile.

Expressing the relevant differential equations in finite difference form together with the load and moment equilibrium conditions, the following matrix equations were obtained [9]:

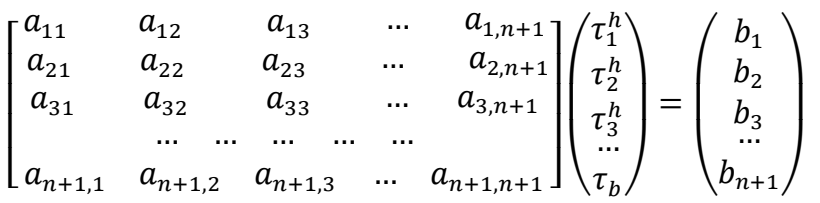

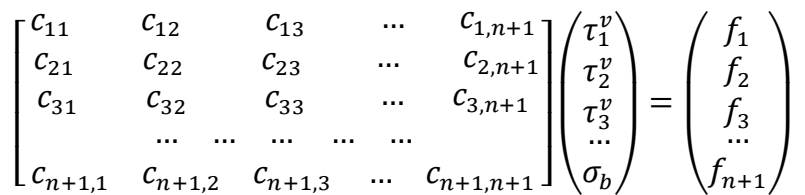


where, $a_{i j}$ and $c_{i j}$ are the elements of the relevant matrices, while $b_{i}$ and $f_{i}$ are the augment vectors. The equations (9) and (10) above has been utilized to evaluate the no-slip values of unknown horizontal shear stress components $\tau_{i}^{h}$ which are compared with their relevant yield values. In case the yield values are exceeded, the stress component is replaced by the yield values and the values for the rest of the unslipped elements are determined. The procedure is repeated in an iterative technique until the desired convergence is attained. A similar technique was followed to evaluate the unknown vertical shear stress components $\tau_{i}^{v}$. To obtain the resultant shear stress, a vector method has been employed, as shown in Fig. 1(d). The resultant shear stress on a typical $i^{\text {th }}$ pile element is given by [9]:

$\tau_{i}^{r}=\left[\left(\tau_{i}^{h}\right)^{2}+\left(\tau_{i}^{v}\right)^{2}\right]^{0.5}$

The solution for combined axial and torsional loads is arrived at by following iterative technique using Equations (9) to (10).

\subsection{Cyclic Torsion}

The analysis for pile-soil interaction is extended to account for cyclic torsion under static loading. In this case, the imposed torque $T_{\text {top }}$ is considered to be a periodic function of time. In reality, the time-pattern of variation may be of various forms. The simplest form is two-way symmetrical sinusoidal loading, expressed as:

$T_{\text {top }}=T_{0} \sin (2 \pi f t)$

where, $T_{0}$ is the amplitude and $f$ is the frequency of applied cyclic torsional load. The cyclic load induces reversal in the horizontal component of the shear stress $\left(\tau_{i}^{h}\right)$ and the base shear stress $\left(\tau_{b}\right)$. Such stress reversal initiates progressive alteration in the strength and stiffness of surrounding soil [10]. Also, the strain rate induced by cyclic load frequency alters the pile-soil interactive performance [11]. The resulting alteration in soil strength and stiffness has been expressed by a term 'soil degradation factor' $\left(D_{i}^{S}\right)$ defined as the ratio of post-cyclic to pre-cyclic values of the relevant soil parameter. Mathematically, the soil degradation factor is given by [12]:

$D_{i}^{S}=\left[1+F_{R} \log _{10}\left(\frac{\lambda_{i}}{\lambda_{r}}\right)\right] N^{-t_{i}}$

where, $F_{R}$ is a non-dimensional loading factor, $\lambda_{i}$ is the loading rate for $i^{\text {th }}$ element, $\lambda_{r}$ is a reference loading rate, $N$ is the number of cycles and $t_{i}$ is a nondimensional degradation parameter. For clay, $0<F_{R}<1.0$, while for sand, $F_{R}=0$. The parameter $t_{i}$ is defined as:

$t_{i}=\frac{\gamma_{i}}{a_{s}+b_{s} \gamma_{i}}$

where, $\gamma_{i}$ is the nodal shear strain, while $a_{s}$ and $b_{s}$ are the hyperbolic cyclic soil parameters. In this numerical model, the analysis has been performed by quasi-static technique instead of cycle-by-cycle method. The detailed methodology with computational steps has been published elsewhere [12, 13]. A computer software is developed using FORTRAN 90 to carry out the computational steps. The flow-chart of the software is presented in Fig.2. The software is based on iterative techniques with several major and minor loops. Separate subroutines were written for static and cyclic analyses. However, the program is based on explicit fast LaGrange finite difference technique, hence cannot be combined with any other numerical technique like the finite element method.

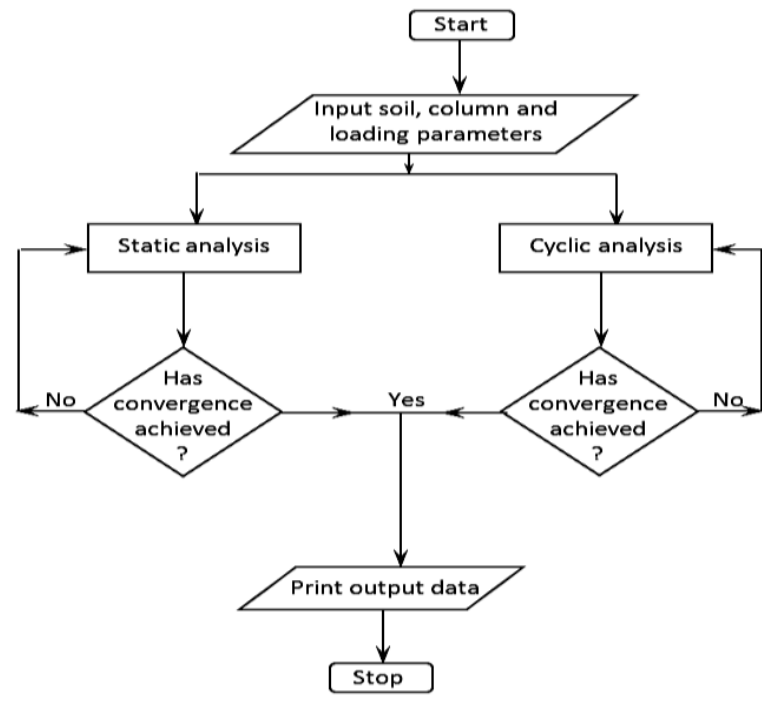

Fig.2. Flow-chart of the computer software

\subsection{Results and Discussions}

Poulos [14] developed a numerical model for torsional response of piles and simultaneously carried out laboratory investigations. Solid aluminum model piles were placed in saturated soft kaolin clay to create the cylindrical model piles. The relations between the applied torque and the angle of twist obtained from the present model have been compared with the numerical and experimental results, as shown in Fig.2. The data taken are same as existing literature [14] and they are presented in Table 1. In Fig.3, the numerical results are compared with the laboratory experimental data of ground-level torquetwist response of model piles. More details of the testing are available from the existing literature [14]. The computed curves are observed to be in reasonably fair agreement with the existing results. The hyperbolic soil model (i.e., $R_{f}=0.95$ ) is closer to the existing data, compared to the linear soil model (i.e., $R_{f}=0$ ). Sudden alteration in soil stress near yield and effect of shear creep are the possible reasons for deviation.

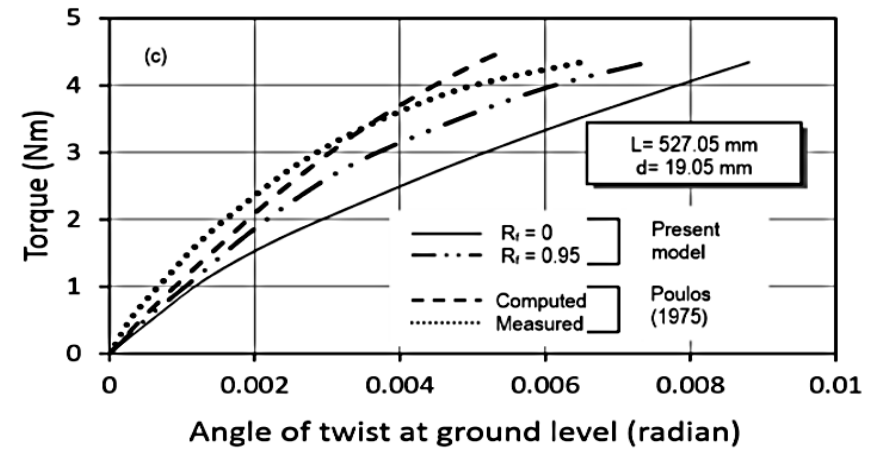

Fig.3. Comparison of computed torque-twist response with available data of Poulos [14] 
Table 1: Computational data for validation

\begin{tabular}{|c|c|c|c|c|}
\hline \multicolumn{2}{|c|}{ Pile data } & \multicolumn{3}{c|}{ Soil data } \\
\hline Length & Diameter & $\begin{array}{c}\text { Limiting } \\
\text { shear } \\
\text { stress }\end{array}$ & $\begin{array}{c}\text { Initial } \\
\text { tangent } \\
\text { modulus }\end{array}$ & $\begin{array}{c}\text { Poisson's } \\
\text { ratio }\end{array}$ \\
\hline $\begin{array}{c}527 \\
\mathrm{~mm}\end{array}$ & $19 \mathrm{~mm}$ & $\begin{array}{c}0.0163 \\
\mathrm{MN} / \mathrm{m}^{2}\end{array}$ & $\begin{array}{c}2.73 \\
\mathrm{MN} / \mathrm{m}^{2}\end{array}$ & 0.5 \\
\hline
\end{tabular}

Cudmani and Gudehus [15] conducted a laboratory model study on the response of a steel hollow pipe pile in loose sand subjected to cyclic twist. The top of the pile was subjected to two-way symmetric cyclic sinusoidal twist. The test data (Table 2) are utilized for comparison of computed results with the test observations, as shown in Fig.4. The computed results match well with the test data. With increasing load cycles, the peak shear stress is observed to progressively degrade with a stabilizing trend. The deviation of computed results has been found to be minimum for $R_{f}=0.85$ at $z / L=0.83$. For $N=15$ and $z / L=0.5$, the deviation is observed to be maximum.

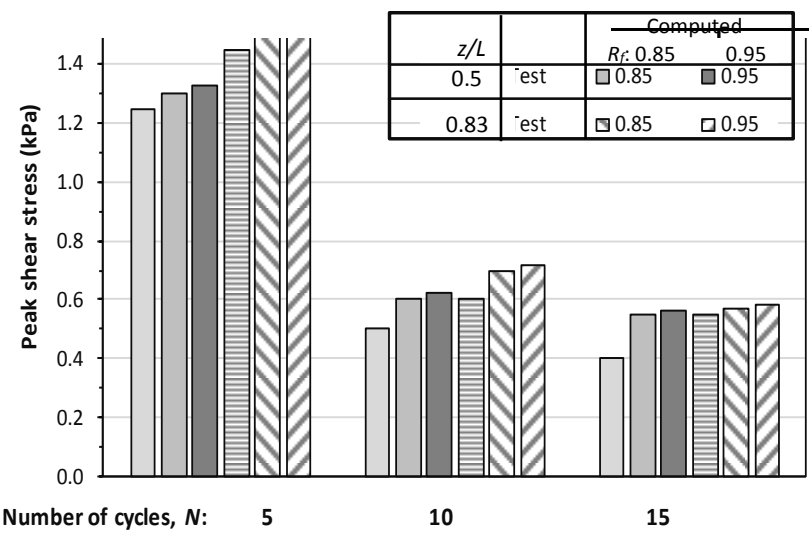

Fig.4. Comparison of computed results with test data of Cudmani and Gudehus [15]

Table 2: Input data

\begin{tabular}{|c|c|c|c|}
\hline \multirow{7}{*}{ Soil } & \multicolumn{2}{|c|}{ Unit weight } & $18.5 \mathrm{kN} / \mathrm{m}^{3}$ \\
\hline & \multicolumn{2}{|c|}{ Effective friction angle $\left(\phi^{\prime}, \delta_{s}\right)$} & $33^{\circ}, 23^{\circ}$ \\
\hline & \multicolumn{2}{|c|}{$K_{0}$} & 0.8 \\
\hline & \multicolumn{2}{|r|}{$G_{t 0}$} & $21 \mathrm{MPa}$ \\
\hline & \multicolumn{2}{|r|}{$\eta_{g}$} & 0 \\
\hline & \multicolumn{2}{|c|}{ Poisson's ratio } & 0.3 \\
\hline & \multicolumn{2}{|c|}{$a_{s}, b_{s}$} & $0.12,2.58$ \\
\hline \multirow{6}{*}{ Pile } & \multicolumn{2}{|c|}{ Embedded length } & $0.9 \mathrm{~m}$ \\
\hline & \multirow{2}{*}{$\begin{array}{l}\text { Cross } \\
\text { section }\end{array}$} & External diameter & $0.1 \mathrm{~m}$ \\
\hline & & Wall thickness & $0.0084 \mathrm{~m}$ \\
\hline & \multirow{2}{*}{$\begin{array}{c}\text { Elastic } \\
\text { properties }\end{array}$} & Young's modulus & $210 \mathrm{GPa}$ \\
\hline & & Rigidity modulus & $91 \mathrm{GPa}$ \\
\hline & \multicolumn{2}{|c|}{ Unit weight } & $78 \mathrm{kN} / \mathrm{m}^{3}$ \\
\hline \multirow[t]{2}{*}{ Load } & \multicolumn{2}{|c|}{ Frequency } & $0.246 \mathrm{~Hz}$ \\
\hline & \multicolumn{2}{|r|}{$V_{t o p}$} & 0 \\
\hline & \multicolumn{3}{|c|}{ Source of data are given elsewhere [12] } \\
\hline
\end{tabular}

In the above study, the salient features of the solutions adopted against the cyclic torsional load on piles are summarized. The proposed solutions are validated with the available experimental results of available literature [14-15], where the small-scale model piles were tested in test beds with remoulded clay and sand respectively. For numerical analysis of these test results, the input data taken as same as those reported in the relevant literature. The solution proposed is based on boundary element modelling. This method is easier and computationally faster than conventional analytical and finite element methods. Thus, the adopted method is computationally efficient in terms of accuracy, computing time and hard disk memory space used.

\section{Soft Ground Improvement}

Infrastructures built on soft, compressible soil are likely to collapse due to bearing capacity failure or excessive settlement of the supporting foundations. This necessitates improving the strength and stiffness of soft ground. Among various methods of ground improvement, stone column installation is one of the most often used and acceptable techniques worldwide [16].

The process entails boring vertical drains through the weak soil and filling them with stone particles of desired specifications. Because of their greater strength and stiffness in comparison to the surrounding subsoil, stone columns not only act as reinforcement for soft soil strata, but they also assist in significantly faster consolidation than conventional prefabricated vertical drains due to their larger diameter and higher hydraulic conductivity. The stone columns are preferable to pile foundations since they are more environmentally friendly [17].

The load transfer and consolidation characteristics of stone column improved soft ground are highly complex and requires advanced mathematical tools to arrive at specific solutions [18]. The detailed solution technique has been presented below.

\subsection{Mathematical Modelling}

The unit cell analogy with free strain hypothesis has been adopted in the mathematical model, as shown in Fig.5. While the salient features and details of the model have been published elsewhere [19-22], the basic methodology adopted is briefly described herein.

In the mathematical model, the influence of arching, clogging, smear and column lateral deformation have been considered. So far as the load transfer mechanism is concerned, the column stiffness compared to its surrounding soil imparts an arching effect which produces a parabolic vertical stress distribution on the ground surface. The relevant expression is given as:

$$
\begin{aligned}
& \frac{w_{c}}{w\left(r_{c}\right)}=n_{s} \\
& w(r)=\left[1-\left(N_{r}-\frac{r}{r_{c}}\right)^{2} F_{s}\left(n_{s}, r_{e}, r_{c}, \bar{w}\right)\right] w\left(r_{e}\right)
\end{aligned}
$$

where, $w_{c}$ and $w(r)$ are the vertical stress on the column and the soil at a radial distance of $r, n_{s}$ is the stress concentration ratio, $N_{r}=r_{e} / r_{c}$ and the stress function $F_{s}$ is an algebraic function of the parameters $n_{s}, r_{e}, r_{c}$ and $\bar{w}$.

The term $\bar{w}$ is the average vertical stress on ground surface, given by:

$\bar{w}=\frac{w_{c}}{N_{r}^{2}}+\frac{2}{r_{e}^{2}} \int_{r_{c}}^{r_{e}} r w(r) d r$ 


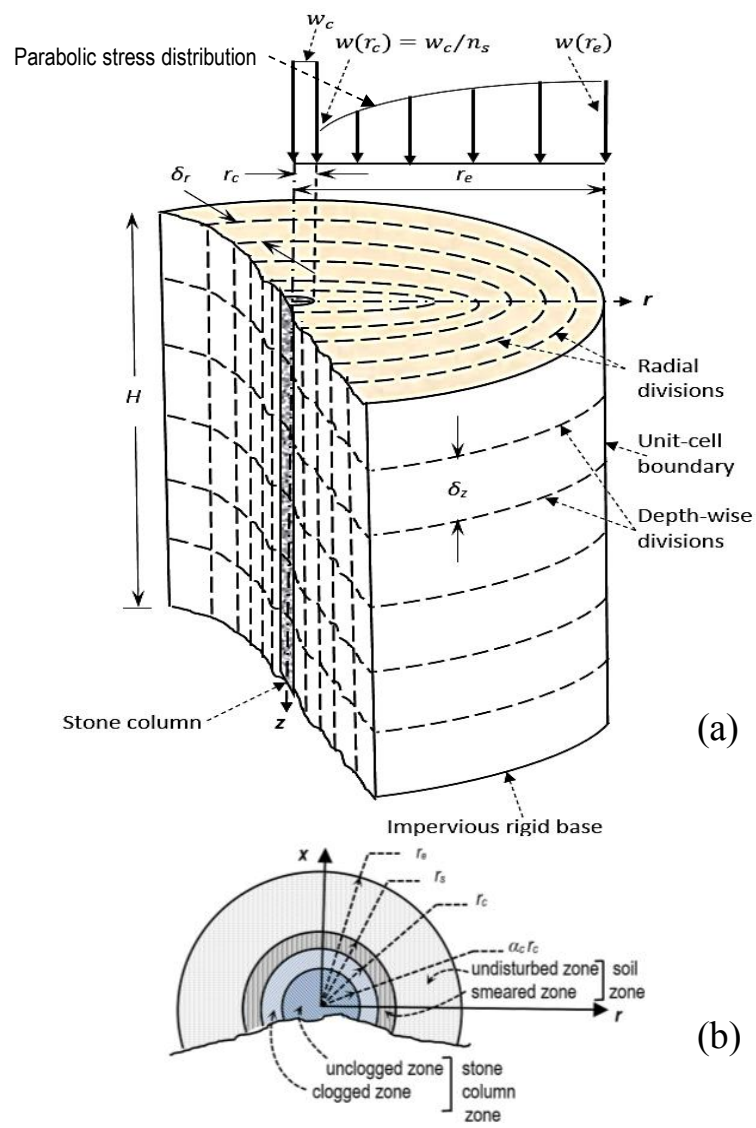

Fig.5. Idealized model: (a) Numerical scheme, and

(b) Unit cell cross section.

To analyze the consolidation characteristics, a numerical scheme has been employed, in which the unit cell is equally discretized radially and depthwise into a finite number of elements (see Fig.5a). At the same time, the computation time $t_{c}$ is also divided into equal number divisions. If $n_{r}, n_{z}$ and $n_{t}$ are the number of divisions along radial, depth and time axes, so that the thicknesses of each of the relevant elements are as follows:

$\delta_{r}=\frac{r_{e}-r_{c}}{n_{r}-1} ; \quad \delta_{z}=\frac{H}{n_{z}-1} ; \quad \delta_{t}=\frac{t_{c}}{n_{t}-1}$

The cross section of the unit cell has two distinct zones: soil zone and column zone. The soil zone consists of undisturbed and smear zones, while the column zone contains unclogged and clogged zones (see Fig. 5b).

Although the soft soil consolidation consists of both radial and vertical components, the radial consolidation has been predominant. Hence, the governing differential equation for radial consolidation is given as [23]:

$\left[\frac{k_{h}}{m_{v} \gamma_{w}}\left(\frac{\partial^{2}}{\partial r^{2}}+\frac{1}{r} \frac{\partial}{\partial r}\right)-\frac{\partial}{\partial t}\right] u_{r t}=0$

where, $k_{h}$, is the soil permeability in horizontal direction, $m_{v}$ is the soil compressibility, $\gamma_{w}$ is the unit weight of water, $t$ is the time and $u_{r t}$ is the excess pore water pressure at the nodal point $(r, t)$ in the space-time frame. Expanding the differential equation by finite difference technique and applying appropriate boundary conditions, the following matrix equation is obtained: $\left[\begin{array}{cccc}p_{11} & p_{12} & \ldots & p_{1, n_{r}} \\ p_{21} & p_{22} & \ldots & p_{2, n_{r}} \\ \ldots & \ldots & \ldots & \ldots \\ p_{n_{r} n_{t}, 1} & p_{n_{r} n_{t}, 2} & \ldots & p_{n_{r} n_{t}, n_{r} n_{t}}\end{array}\right]\left[\begin{array}{cccc}u_{11} & u_{12} & \ldots & u_{1, n_{r}} \\ u_{21} & u_{22} & \ldots & u_{2, n_{r}} \\ \ldots & \ldots & \ldots & \ldots \\ u_{n_{r} n_{t}, 1} & u_{n_{r} n_{t}, 2} & \ldots & u_{n_{r} n_{t}, n_{r} n_{t}}\end{array}\right]\left(\begin{array}{c}q_{1} \\ q_{2} \\ \ldots \\ q_{n_{r} n_{t}}\end{array}\right)$

where, $p_{i j}$ is a typical element of the coefficient matrix and $q_{i}$ is the augment vector. Solution to this Equation yields the values of unknown excess pore water pressures $\left(u_{r t}\right)$. In the analysis, the modified Cam-clay model has been incorporated [24]. Accordingly, the soil compressibility is expressed as follows:

$m_{v}=\frac{-3 \lambda}{F_{p}}\left(p_{0}^{\prime} / p_{a v}^{\prime}\right)$

where, $\lambda$ is the slope of the $e$-ln $p^{\prime}$ curve, $p_{0}^{\prime}$ and $p_{a v}^{\prime}$ are the mean and average values of effective stresses in soil, and the function $F_{p}$ is related to the initial void ratio of soil $\left(e_{o}\right)$ and is given as follows:

$F_{p}=\frac{1}{\left(1+2 K_{s}\right)\left[1+e_{o}-\lambda \ln \left(\frac{p_{a v}^{\prime}}{p_{0}^{\prime}}\right)\right]}$

where, $K_{s}$ is the lateral earth pressure coefficient. The vertical deformation of soil at a typical nodal point $(r, z, t)$ and its average value are given as:

$\rho_{r z t}^{v}=\int_{z}^{H}\left(-\int_{0}^{t} m_{v} \frac{\partial}{\partial t} u_{r t} d t\right) d z$

$\rho_{a v}^{v}=\frac{2}{N_{r}^{2}-1}\left[\int_{r_{c}}^{r_{e}} \rho_{r z t}^{v} r d r\right]_{z=0}$

The stone column improved soft ground occasionally supports transport infrastructure, such as railways and highways. Regular passage of traffic induces cyclic loading on the reinforced soil. In such circumstances, the problem is required to be extended to account for the influence of cyclic loading. In the current mathematical model, the modified Cam-clay model with cyclic stress path analysis associated with gradual contraction of yield surface has been incorporated. The imposed cyclic loading has been simplified as regular sinusoidal having specified frequency and stress amplitude. The following expression has been used to carry out the analysis [25]:

$\frac{p_{2}^{\prime}}{p_{1}^{\prime}}=\left[\frac{1+\left(\frac{q_{2} / p_{2}^{\prime}}{M}\right)^{2}}{1+\left(\frac{q_{1} / p_{1}^{\prime}}{M}\right)^{2}}\right]^{\left(\frac{\kappa}{\bar{\lambda}}-\lambda\right)}$

where, $p_{1}^{\prime}, p_{2}^{\prime}, q_{1}$ and $q_{2}$ are the relevant mean effective and deviatoric stresses for corresponding stress points ' $l$ ' and ' 2 ' in the $p^{\prime}-q$ space, $\mathrm{M}$ is the slope of the critical straight line and $\kappa$ is the slope of the unloading curve in $e$ $\ln p^{\prime}$ space.

The entire computation has been carried out by developing a user-friendly computer software written in FORTRAN 90.

\subsection{Results and Discussions}

The results obtained from current mathematical model has been compared with the field test data carried out at an Australian site comprising of a group of stone columns installed in a soft marine clay deposit, subjected to imposed loading by earthen embankment. The embankment was constructed in stages with several rest periods. To cross check, a 2-dimensional simplified finite element analysis done by PLAXIS 2D software has been carried out as well. 
The data relevant to soil and column are taken from the published literature [26]. Fig.6 depicts the settlement-time response of the reinforced soft ground. Fig.6 is a plot of time-settlement response of reinforced ground surface, where the settlement is plotted in linear scale, while the time axis is in logarithmic scale. The plotted variations have been observed to be curvilinear.

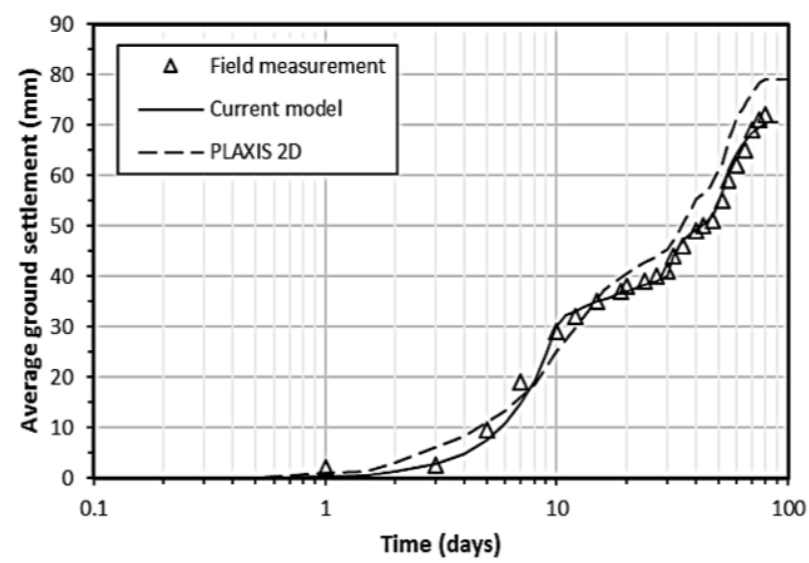

Fig.6. Comparison of computed results with field data and PLAXIS 2D analysis

As observed, the results obtained by the obtained by the current mathematical model matches closely well with the field data, while the finite element model results deviate to some extent. In the case of $0<t<10$ days, some deviation of the results obtained from the current model has been noted, but there is excellent agreement thereafter.

The results obtained from the current mathematical model is compared with the laboratory test data relevant to cyclic plate load tests with reinforced soft clay samples. The laboratory investigation was carried out by Raju et al. [27]. The bar charts relevant to the residual settlement against different peak load intensities are presented in Fig.7. As observed, the results obtained by the present mathematical model matches well with the measured data. As the peak load intensity increased from $88 \mathrm{kPa}$ to $324 \mathrm{kPa}$, the residual settlement ranged from $0.12-0.9 \mathrm{~m}$ for the experiments as against $0.075-0.87 \mathrm{~m}$ for the computation.

The input data for these analyses corresponding to soil column and loading are taken from the relevant literature [26-28] and are presented in the Table 3 below.

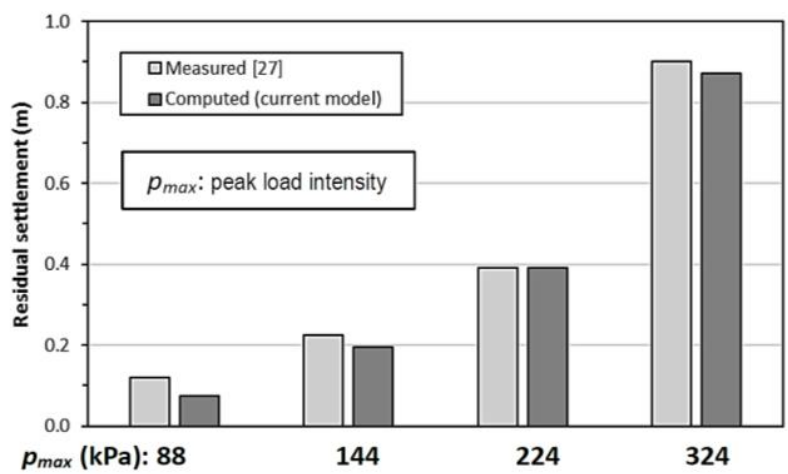

Fig.7. Comparison of computed results with test data of Raju et al. [27]
Table 3: Input data for computations

\begin{tabular}{|c|c|c|c|}
\hline Materials & Parameter & {$[26]$} & {$[27]$} \\
\hline \multirow{4}{*}{$\begin{array}{c}\text { Soft } \\
\text { clay }\end{array}$} & $H(\mathrm{~m})$ & 10 & 0.3 \\
\cline { 2 - 4 } & $k_{h}(\mathrm{~m} / \mathrm{s})$ & $1 \times 10^{-9}$ & $1 \times 10^{-9}$ \\
\cline { 2 - 4 } & $\begin{array}{c}\text { Initial } m_{v} \\
\left(\mathrm{~m}^{2} / \mathrm{N}\right)\end{array}$ & $3 \times 10^{-6}$ & $1.2 \times 10^{-8}$ \\
\cline { 2 - 4 } & $e_{0}$ & $1.0-3.0$ & 1.55 \\
\cline { 2 - 4 } & $\lambda$ & $0.5-0.7$ & 0.15 \\
\cline { 2 - 4 } & $\kappa$ & - & 0.05 \\
\hline \multirow{4}{*}{$\begin{array}{c}\text { Stone } \\
\text { column }\end{array}$} & $r_{c}(\mathrm{~m})$ & 0.5 & 0.015 \\
\cline { 2 - 4 } & $r_{e}(\mathrm{~m})$ & 1.13 & 0.075 \\
\cline { 2 - 4 } & $n_{s}$ & 4.0 & 3.0 \\
\cline { 2 - 4 } & Clogging & $\alpha_{c}=0.9$ & $\alpha_{c}=1.0$ \\
& & $\alpha_{k}=0.9$ & $\alpha_{k}=1.0$ \\
\hline \multirow{3}{*}{ Embankment } & Base & $15 \mathrm{~m} \mathrm{x} \mathrm{15}$ & - \\
& & $\mathrm{m}$ & - \\
\cline { 2 - 4 } & Height & $3 \mathrm{~m}$ & - \\
\cline { 2 - 4 } & Unit wt. & $20 \mathrm{kN} / \mathrm{m}^{3}$ & - \\
\hline
\end{tabular}

The numerical model developed was compared with and without clogging effect, after [21]. The data is taken from [26]. The numerical results are shown in Fig.8. It is observed that consideration of clogging initiates a better prediction closer to field observations.

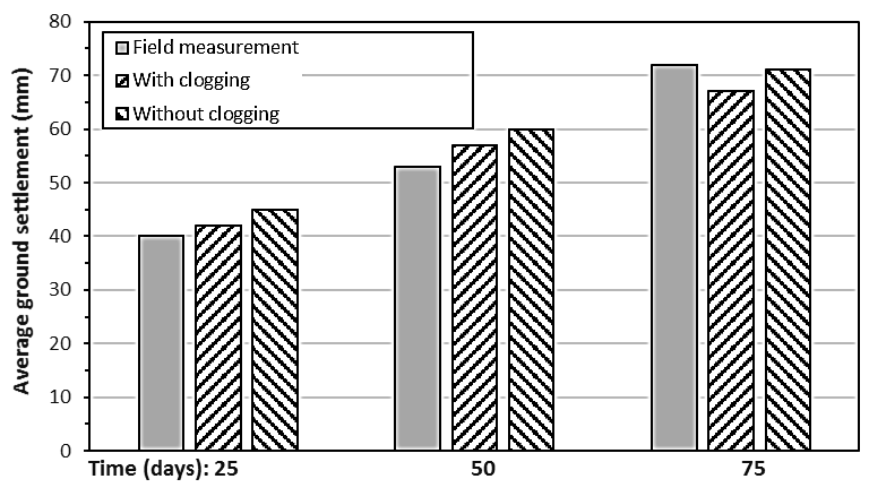

Fig.8. Comparison of field data and numerical results with and without clogging

\section{Coastal Groundwater Management}

From the perspective of saltwater intrusion, coastal zones require effective management in order to provide enough storage and supply of groundwater to inhabitants. Withdrawal of fresh groundwater for domestic, irrigational, or industrial reasons causes inward advancement of the interface between freshwater and saltwater due to the demand for hydraulic equilibrium, which results in the introduction of saline water into the groundwater system. Excessive precipitation in onshore areas, on the other hand, causes freshwater to drain back into the sea, resulting in the introduction of undersea groundwater discharge [29]. The flow characteristics through aquifer material are dependent on a variety of parameters, including hydraulic conductivity, piezometric head, density stratification of flow, and other factors, and can be either linear or non-linear [30].

A simple analytical technique has been devised to aid in the effective management of coastal groundwater. This technique can be used quickly and easily. The approach is suitable for rural and suburban coastal areas with low to 
medium population density, significant annual rainfall, acceptable aquifer permeability, and shallow fresh groundwater depth. While the details of the proposed method have been published elsewhere [31], the mathematical techniques and analyses are provided briefly here. The withdrawal of fresh groundwater by pumping it through vertical wells causes upconing, which reduces the capacity of the wells to release enough water to meet the local water demand. However, when the withdrawal is accomplished by horizontal wells, the discharge capacity is greatly increased prior to the initiation of upconing operations. It is standard practice for such horizontal wells to be connected at their ends to a vertical pipeline, which is referred to as a 'qanat' structure. The horizontal wells are termed as legs and the vertical pipeline is called riser. A qanat may consist of $N_{L}$ number of horizontal wells, $N_{L}$ being a positive integer greater than unity. For example, when $N_{L}=4$, it is termed as a 4-legged qanat. Schematic diagrams of qanats are shown in Fig.9.

With reference to the groundwater withdrawal in a typical coastal area, as shown in Fig.10, the discharge through the qanat is obtained from the principle of hydraulics, given by [31]:

$Q=\frac{2 \pi k_{h} H s}{\ln \left(F_{q}\right)}$

where, $k_{h}$ is the permeability of the aquifer along horizontal direction, $H$ is the total aquifer thickness $\left(=H_{f}+H_{s}\right)$ and $F_{q}$ is a qanat function given as,

$F_{q}=\frac{1}{\sqrt{2}}\left[\sqrt{1+\sqrt{1+\frac{4 R^{4}}{L_{q}^{4}}}}+\sqrt{-1+\sqrt{1+\frac{4 R^{4}}{L_{q}^{4}}}}\right]\left(\frac{2 \beta \omega^{2}+\frac{\beta H^{2}}{2}}{H r_{q}}\right)^{\frac{2 \beta H}{L_{q}}}$

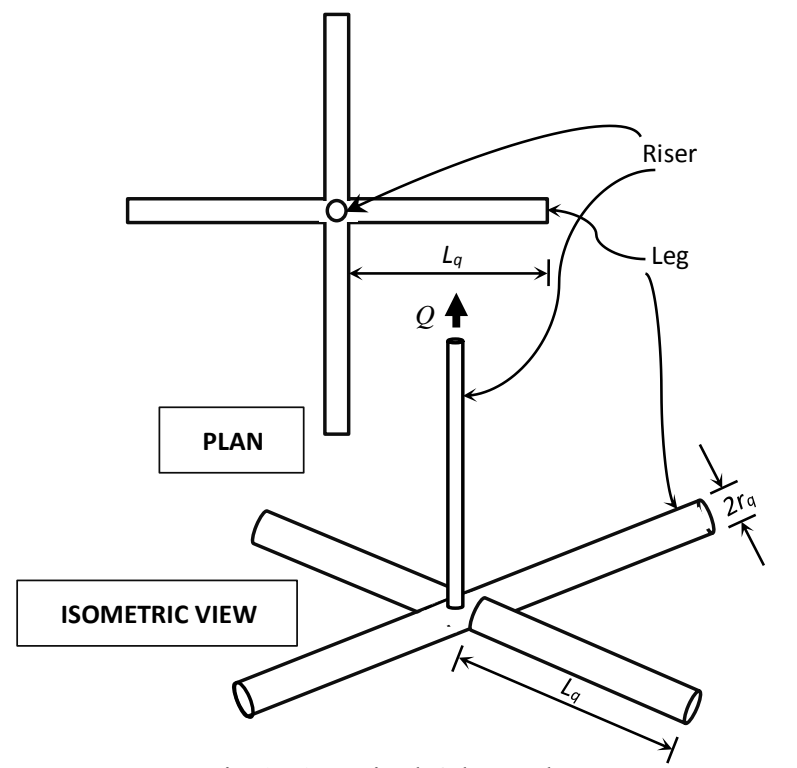

Fig.9. A typical 4-legged qanat

where, $R$ is the radius of influence, $\beta=\sqrt{ }\left(k_{h} / k_{v}\right)$, $k_{v}$ is the permeability of aquifer along vertical direction and $\omega$ is the off-centred eccentricity of the well centre in the vertical aquifer plane.

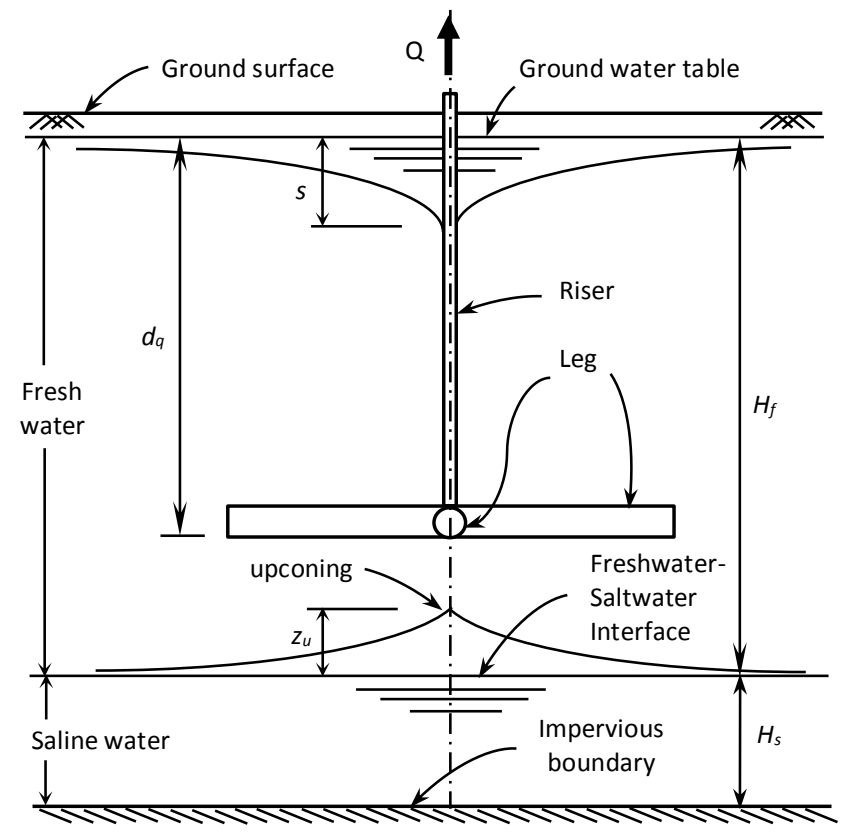

Fig.10. Hydraulic parameters relevant to groundwater withdrawal in a typical salinity affected coastal area

The discharge $Q$ attains its maximum value when the drawdown is optimum, i.e., $s=d_{q}-2 r_{q}$; the maximum discharge is therefore given by:

$Q_{\max }=\frac{2 \pi k_{h}\left(H_{f}+H_{s}\right)\left(d_{q}-2 r_{q}\right)}{\ln \left(F_{q}\right)}$

Carrying out the analysis from the viewpoint of upconing, the discharge assumes a maximum value when the total upconing $z_{u}=H_{f}-d_{q}$, which yields the maximum discharge as [31],

$Q_{\text {max }}=2 \pi \pi k_{h}\left(\frac{\gamma_{s}}{\gamma_{f}}-1\right)\left(H_{f}-d_{q}\right)$

where, $\gamma_{s}$ and $\gamma_{f}$ are the unit weights of the saline water and fresh water, respectively.

The allowable discharge from the qanat should not exceed the minimum of the above two values of $Q_{\max }$ obtained by Equations (26) and (27).

Although the allowable discharge is significantly improved by adopting qanats, compared to conventional vertical wells, it cannot fully eliminate the upconing hazard. Unless the freshwater-saltwater interface is pushed backward, withdrawal of fresh groundwater always initiates onshore advancement of interface, producing saline water intrusion. In the proposed technique, this is achieved by the freshwater rainwater through the recharge ponds and recharge wells, specifically designed for the purpose.

The factor of safety $\left(F_{r}\right)$ for coastal groundwater management in a specific locality is given by [31]:

$F_{r}=V_{r} / V_{w}$

where, $V_{r}$ is the volume of water available annually for recharge and $V_{w}$ is the volume of water annually required to be withdrawn in the locality under consideration. Ideally, the groundwater management technique should be designed in such a manner that the 
value of $F_{r}$ is slightly above unity. This can be achieved by properly adjusting the sizes of qanat and recharge ponds and wells.

The model developed has been utilized to design the groundwater management in a coastal community. The study location is an educational institute situated at a coastal region of the district of East Midnapore of the state of West Bengal, India. With the given data for community water requirement, hydrogeology and precipitation history, the model has been successfully applied in the study area. The design of qanat has been highlighted in the Fig.11. Based on the observations, appropriate values of the qanat dimensions, i.e., depth, length and radius $\left(d_{q}, L_{q}\right.$ and $\left.r_{q}\right)$ should be chosen. The details of design methodology have been published elsewhere [31].

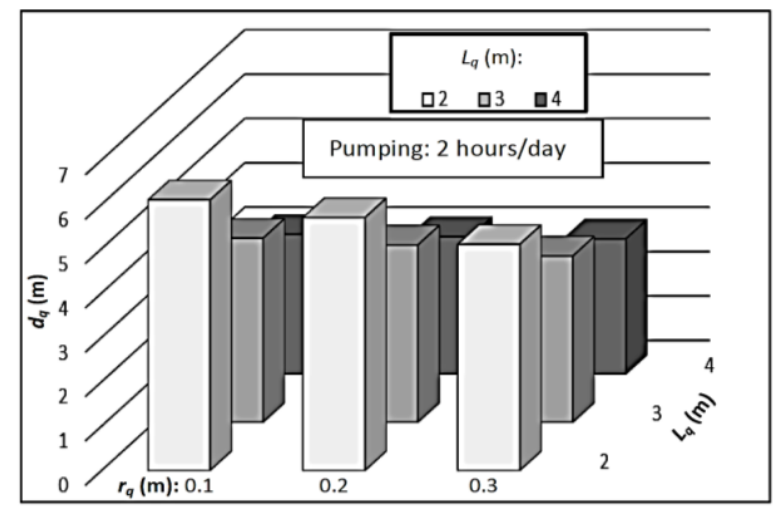

Fig. 11. Design of a typical qanat

\section{Novelty and Importance}

In recent years, significant advancement is evidenced in the field of applied and theoretical mechanics [3235]. Amongst various emerging areas, geotechnical and geoenvironmental engineering is a broad field of research and development. This paper presents indepth analytical and numerical solutions to three important research problems related to geomechanics and geohydraulics. These problems are most relevant to the infrastructural and water resource projects and their solutions are helpful to practicing engineers and scientists working in similar study fields. The solutions and their brief presentations herein are succinct, rigorous and novel. The validations are logical and applicable to practical field.

\section{Conclusions}

The paper presented an in-depth overview of the mathematical solutions used in a variety of research problems in geotechnical and geoenvironmental engineering. A number of issues have been identified, including the torsional pile-soil interactive response, soft ground improvement by stone columns and coastal groundwater management. Advanced analytical and numerical tools were applied to arrive at specific solutions. The computed results were observed to closely match with the experimental data which reveal the accuracy of the models that were developed. The development of these models not only required cutting-edge mathematical rigor, but also a thorough understanding of the fundamental principles of solid and fluid mechanics, such as stress-deformation characteristics, cyclic stress reversals, strength and stiffness degradation of materials, linear and nonlinear groundwater flow, etc.

\section{Acknowledgements}

The research was carried out under the financial supports from various agencies including University Grants Commission, All India Council for Technical Education, Australian Research Council, Australian Government and Pinnacle Educational Trust. Supports have also been received from Coffey Geotechnics and Keller Ground Engineering. Last but not the least, the authors thankfully acknowledge the assistance received from Prof. A. K. Bhattacharya, Prabir Maity and Sankhasubhra Sen of Bengal Engineering and Science University and Prof. B. Indraratna, Prof. C. Rujikiatkamjorn and Firman Siahaan of University of Wollongong.

References:

[1] Murali Krishna, A., Emerging Trends in Geotechnical Engineering, National Workshop, Department of Civil Engineering, Indian Institute of Technology Guwahati, India, 2012.

[2] Zhang, G., Fu, P. and Liang, F., Mathematical and Numerical Modeling in Geotechnical Engineering, Journal of Applied Mathematics, Vol. 2013, No. 123485 , 2014 , http://dx.doi.org/10.1155/2013/123485

[3] Selvadurai, A.P.S., The Analytical Method in Geomechanics, Applied Mechanics Reviews, Vol. 60, pp. 87-106, 2007.

[4] Hicks, M.A., Brinkgreve, R.B.J. and Rohe, A., Numerical Methods in Geotechnical Engineering, CRC Press, 2014.

[5] Isbuga, V., Modeling of pile-soil-pile interaction in laterally loaded pile groups embedded in linear elastic soil layers, Arabian Journal of Geosciences, Vol. 13, No. 322, 2020.

[6] Mu, L., Chen, Q., Huang, M. and Basack, S., Hybrid approach for rigid piled-raft foundations subjected to coupled loads in layered soil, International Journal of Geomechanics, Vol. 17, No. 5, 2017, https://doi.org/10.1061/(ASCE)GM.19435622.0000825

[7] Nghiem, H.M. and Chang, N.Y., Efficient solution for a single pile under torsion, Soils and Foundations, Vol. 59, Issue 1, pp. 13-26, 2020.

[8] Basack, S. and Sen, S., Numerical solution of single piles subjected to pure torsion, Journal of Geotechnical and Geoenvironmental Engineering, Vol.140, Issue 1, pp. 74-90, 2014, https://doi.org/10.1061/(ASCE)GT.19435606.0000964

[9] Basack, S. and Sen, S., Numerical solution of single pile subjected to simultaneous torsional and axial loads, International Journal of Geomechanics, 
Vol.14, Issue 4, 2014, https://doi.org/10.1061/(ASCE)GM. 19435622.0000325

[10] Lee, C.Y., Cyclic response of axially loaded pile groups, Journal of Geotechnical Engineering, 10.1061/(ASCE)0733-9410(1993)119:9(1399), 1399-1413, 1993.

[11] Poulos, H.G., Cyclic axial loading analysis of piles in sand, Journal of Geotechnical Engineering, $\quad 10.1061 /(\mathrm{ASCE}) 0733-$ 9410(1989)115:6(836), 836-852, 1989.

[12] Basack, S. and Nimbalkar, S., Numerical solution of single pile subjected to torsional cyclic load, International Journal of Geomechanics, Vol.17, Issue 8, 2017, https://doi.org/10.1061/(ASCE)GM.19435622.0000905

[13] Nimbalkar, S.S., Punetha, P., Basack, S. and Mirzababaei, M., Piles Subjected to Torsional Cyclic Load: Numerical Analysis, Front. Built Environ., Vol.5, No.24, 2019, doi: 10.3389/fbuil.2019.00024

[14] Poulos, H.G., Torsional response of piles, Journal of Geotechnical Engineering, Vol.101, No.10, pp. 1019-1035, 1975.

[15] Cudmani, R. and Gudehus, G., Settlement of sand due to cyclic twisting of a tube, IUTAM Symposium on Theoretical and Numerical Methods in Continuum Mechanics of Porous Materials, Springer, Dordrecht, Netherlands, pp. 387-396, 2001.

[16] Wang, G., Consolidation of soft soil foundations reinforced by stone columns under time dependant loading, Journal of Geotechnical \& Geoenvironmental Engineering, pp. 1922193110.1061/(ASCE)GT.1943-5606.0000178

[17] Basack, S., Indraratna, B. and Rujikiatkamjorn, C., Analysis of the behaviour of stone column stabilized soft ground supporting transport infrastructure, Procedia Engineering, Vol.143, pp. 347-354, 2016, doi: 10.1016/j.proeng.2016.06.044

[18] Basack, S., Indraratna, B., Rujikiatkamjorn, C. and Siahaan, F., Theoretical and numerical perspectives on performance of stone column improved soft ground with reference to transport infrastructure, In: Indraratna, B., Jian, C. and Rujikiatkamjorn, C. (eds.). Ground Improvement: Case Studies, Elsevier GeoEngineering Book Series, Vol.1, pp. 747-79, 2015, http://dx.doi.org/10.1016/B978-0-08100192-9.00026-0

[19] Indraratna, B., Basack, S., and Rujikiatkamjorn, C., Numerical solution to stone column reinforced soft ground considering arching, clogging and smear effects, Journal of Geotechnical and Geoenvironmental Engineering, pp. 377-394, 2013, 10.1061/(ASCE)GT.1943-5606.0000789

[20] Basack, S., Indraratna, B., and Rujikiatkamjorn,
C., Modeling the performance of stone column reinforced soft ground under static and cyclic loads, Journal of Geotechnical and Geoenvironmental Engineering, 2016, 10.1061/(ASCE)GT.19435606.0001378

[21] Basack, S., Indraratna, B., Rujikiatkamjorn, C., and Siahaan, F., Modeling the stone column behaviour in soft ground with special emphasis on lateral deformation, Journal of Geotechnical and Geoenvironmental Engineering, 2017, 10.1061/(ASCE)GT.1943-5606.0001652

[22] Basack, S., Siahaan, F., Indraratna, B. and Rujikiatkamjorn, C., stone column-stabilized softsoil performance influenced by clogging and lateral deformation: laboratory and numerical evaluation, International Journal of Geomechanics, Vol.18, No.6, 2018, pp. 04018058-1, DOI: 10.1061/(ASCE)GM.1943-5622.0001148

[23] Barron, B. A., Consolidation of fine-grained soil by drain wells, Trans. Am. Soc. Civ. Engrg., Vol. 113, pp. 712-748, 1948.

[24] Roscoe, K. H. and Burland, J. B., On the generalised stress-strain behaviour of 'wet' clay, Engineering plasticity, J. Heyman and F. A. Leckie, eds., Cambridge University Press, pp. 535-609, 1968.

[25] Ni, J., Indraratna, B., Geng, X. Y., Carter, J. P. and Chen, Y. L., Model of soft soils under cyclic loading, International Journal of Geomechanics, 2014, 10.1061/(ASCE)GM.1943-5622.0000411

[26] Basack, S., Indraratna, B., and Rujikiatkamjorn, C., Effectiveness of stone column reinforcement for stabilizing soft ground with reference to transport infrastructure, Geotechnical Engineering Journal of the SEAGS \& AGSSEA, Vol. 49, No.1, pp. 8-14, 2018

[27] Raju, K.V.S.B., Govindaraju, L. and Chandrasekhar, A.S., Cyclic response of stone columns, Int. J. Sci. Eng. Res., Vol. 4, No. 5, pp. 29-32, 2013.

[28] Basack, S. and Nimbalkar, S., Free strain analysis of the performance of vertical drains for soft soil improvement. Geomechanics and Engineering, Vol. 013, No. 6, pp. 963-975, http://dx.doi.org/10.12989/gae.2017.13.6.963

[29] Goswami, G., Basack, S., Mastorakis, N., Saikia, A., Nilo, B. and Ahmed, N., Coastal ground water flow and management: a state-of-the-art review, International Journal of Mechanics, pp. 37-48, 2020, http://doi.org/10.46300/9104.2020.14.5

[30] Basack, S., Goswami, G., Deka, P., Barman, M. K. and Chisi, K., Flow characteristics through saturated soil: experimental study, WSEAS Transactions on Environment and Development, Vol. 16, pp. 198203, 2020, DOI: $10.37394 / 232015.2020 .16 .20$

[31] Basack, S., Bhattacharya, A.K. and Maity, P., A coastal groundwater management model with Indian case study, Proceedings of the Institution of Civil Engineers: Water Management, Vol. 167, Issue WM3, pp. 126-140, http://dx.doi.org/10.1680/wama.12.00008

[32] R. Benocci, S.S., Muchetti, D., Salvi, F., Angelini, G., Brambilla, G. and Zambon., Spatial analysis and 
temporal trend of registered noise complaints in the city of Milan, Italy, International journal of Mechanics, Volume 14, pp. 168-176, 2020

[33] Makanda, G., A Numerical analysis of viscoelastic flow between porous moving walls, WSEAS Transactions on Fluid Mechanics, Volume 14, pp. 15-20, 2019.

[34] Gladkov, S. O. and Bogdanova, S.B., On distribution of speeds and pressures near the surface of rotating discs, WSEAS Transactions on Fluid Mechanics, Volume 14, pp. 8-14, 2019.

[35] Zdeněk, K., Limit states of structures and global sensitivity analysis based on cramér-von mises distance spatial analysis and temporal trend of registered noise complaints in the city of Milan, Italy, International Journal of Mechanics, Volume 14, pp. 107-118, 2020.

\section{Conflict of Interest Statement}

The authors declare that there is no conflict of interest in this paper.

\section{Authors' Contributions}

Sudip Basack is responsible for overall supervision and execution; Ghritartha Goswami conducted the compilation of the work; Sanjay Nimbalkar carried out the writing and revisions.

\section{Creative Commons Attribution License 4.0 (Attribution 4.0 International, CC BY 4.0)}

This article is published under the terms of the Creative Commons Attribution License 4.0

https://creativecommons.org/licenses/by/4.0/deed.en_US 